\title{
Three-Year Longitudinal Association Between Built Environmental Factors and Decline in Older Adults' Step Count: Gaining insights for Age-Friendly Urban Planning and Design
}

\author{
Kimihiro Hino ${ }^{1, *(\mathbb{D})}$, Hiroyuki Usui ${ }^{1}$ and Masamichi Hanazato ${ }^{2}(\mathbb{D}$ \\ 1 Department of Urban Engineering, Graduate School of Engineering, The University of Tokyo, \\ Tokyo 113-8656, Japan; usui@ua.t.u-tokyo.ac.jp \\ 2 Center for Preventive Medical Sciences, Chiba University, Chiba 263-8522, Japan; hanazato@chiba-u.jp \\ * Correspondence: hino@ua.t.u-tokyo.ac.jp; Tel./Fax: +81-3-5841-6225
}

Received: 22 May 2020; Accepted: 11 June 2020; Published: 14 June 2020

\begin{abstract}
This study examined the longitudinal association between the change in the step count of older adults and the neighborhood-built environment (BE) in Yokohama, Japan. We analyzed pedometer data in March 2016 and March 2019 that were acquired from 21,557 older adults aged 65-79 years at baseline, who lived in 758 neighborhoods in Yokohama City and participated in the Yokohama Walking Point Program (YWPP). Six BE variables were computed, for each of which neighborhoods were classified into quartiles. Using multilevel regression analysis, we examined the association between the BE variables, baseline step count, and change in step count. Higher population density, lower intersection density, and the second shortest quartile of the average distance to the nearest railway station were associated with a higher baseline step count. A lower intersection density and shorter average distance to the nearest railway station were associated with a smaller decline. The lowest quartile of population density was inversely associated with step-count decline. In conclusion, the neighborhood BEs were not only associated with their step count at baseline, but also widened the disparity of the step count over the three years. These findings would contribute to creating age-friendly cities where older adults can maintain and promote their health.
\end{abstract}

Keywords: physical activity; neighborhood; multilevel analysis; walkability; compact city

\section{Introduction}

The promotion of regular physical activity (PA) decreases the risk of non-communicable diseases and increases life expectancy [1]. Older adults, in particular, can benefit from regular PA to maintain their physical, social, and mental health as well as to decrease the risk of dementia [2,3]. To promote PA in a population, it is essential to achieve a walkable built environment (BE) through appropriate planning of land use and transportation [4,5]. The well-known attributes of a walkable BE, known as the "5Ds" (i.e., Density, Diversity, Design, Destination Accessibility, and Distance to Transit) [6,7], would be more impactful for older adults, as their geographic reach of activity space is smaller and they spend more time in their neighborhoods than individuals of other age groups [8,9].

Previous cross-sectional studies have examined associations between the walking behaviors and/or PA of older adults and the 5D attributes: density (e.g., population density and household density) [10,11], diversity (e.g., land-use mix and green land use) [10,12-14], design (e.g., intersection density and street connectivity) $[6,10,11,13,14]$, destination accessibility (e.g., accessibility to amenities, commercial facilities, and services) [10,13-15], and distance to transit [16]. However, cross-sectional studies cannot avoid the self-selection bias, and longitudinal studies are needed to establish causal 
relationships between the BE and PA $[17,18]$. Thus, evidence from longitudinal studies is required to confirm the observed associations between the BE and PA that were reported from cross-sectional studies [13].

A few longitudinal studies have examined the relationship between the change of walking behaviors and/or PA of older adults and BE factors, that is, access to PA facilities [19], proximity to parks and trails [20], proximity to functional spaces (e.g., supermarkets and PA facilities) [21], proximity to services and amenities [22], residence in greener neighborhoods [23], and combined walkability score [24]. However, these studies used only some of the 5D attributes and could not consider complex interrelated BE factors in cities. Moreover, there are still few studies that use objectively measured PA data from a large sample [25], although self-serving bias cannot be avoided when using self-reported data on PA [26].

This longitudinal study aimed to examine the association between the change in older adults' step count over a three-year period and the neighborhood BE in Yokohama, Japan. This study is unique in that it is longitudinal in nature, objectively measures step counts from a large sample, and analyzes all $5 \mathrm{D}$ attributes of the BE.

\section{Materials and Methods}

\subsection{Target Area}

The target area of this study comprised the 758 neighborhoods (postal code areas) that constitute Yokohama City, the second most populous city in Japan with a population of approximately 3.75 million people, of whom $27.1 \%$ were in the 65 years or older age group as of January 2020. Yokohama City is one of the leading municipalities in Japan with age-friendly urban planning, design, and policies. Situated 30-40 km from Tokyo, the city's railway network has been developed with many lines toward central Tokyo and comprises 157 railway stations (Figure 1). Similarly, as in other big cities in Japan, the railway stations in Yokohama host a comprehensive set of services and products [27] and thereby serve as a destination that is frequented by residents. The expansion of the local bus network around the railway stations ensures that approximately $90 \%$ of the citizens can access the railway stations in less than $15 \mathrm{~min}$.

\subsection{Measurement of Step Count Data}

Step count data were obtained from older participants (aged 65-79 years) of the Yokohama Walking Point Program (YWPP), launched by the city authorities in November 2014 to encourage citizens to inculcate measures that could improve their health and healthy life expectancy. The program provided free pedometers (Omron HJ-326F, Japan) for adult volunteers (aged $\geq 18$ years) who live and/or work in Yokohama. That was why we selected Yokohama City as the target area, as such large-sample data were not available in other Japanese cities. Participants were awarded points on the basis of their step count by scanning their pedometers via special readers that were installed at approximately 1000 stores and other facilities in the city. The accumulation of a certain number of points made participants eligible to win prizes. The scanned data were transferred to an online data server, and this allowed participants to monitor their step count and ranking among all of the program participants on the website [28].

We used the data obtained for March 2016 (baseline) and March, 2019 (endpoint). Yokohama has a mild climate in March, with average minimum and maximum temperatures of 7.0 and $14.5^{\circ} \mathrm{C}$ in March 2016 and 7.3 and $15.1^{\circ} \mathrm{C}$ in March 2019, respectively [29]. The average step count of participants in the 65 or older age group in March 2016 was the seventh highest for the preceding 12 months, starting from April 2015 [30]. 


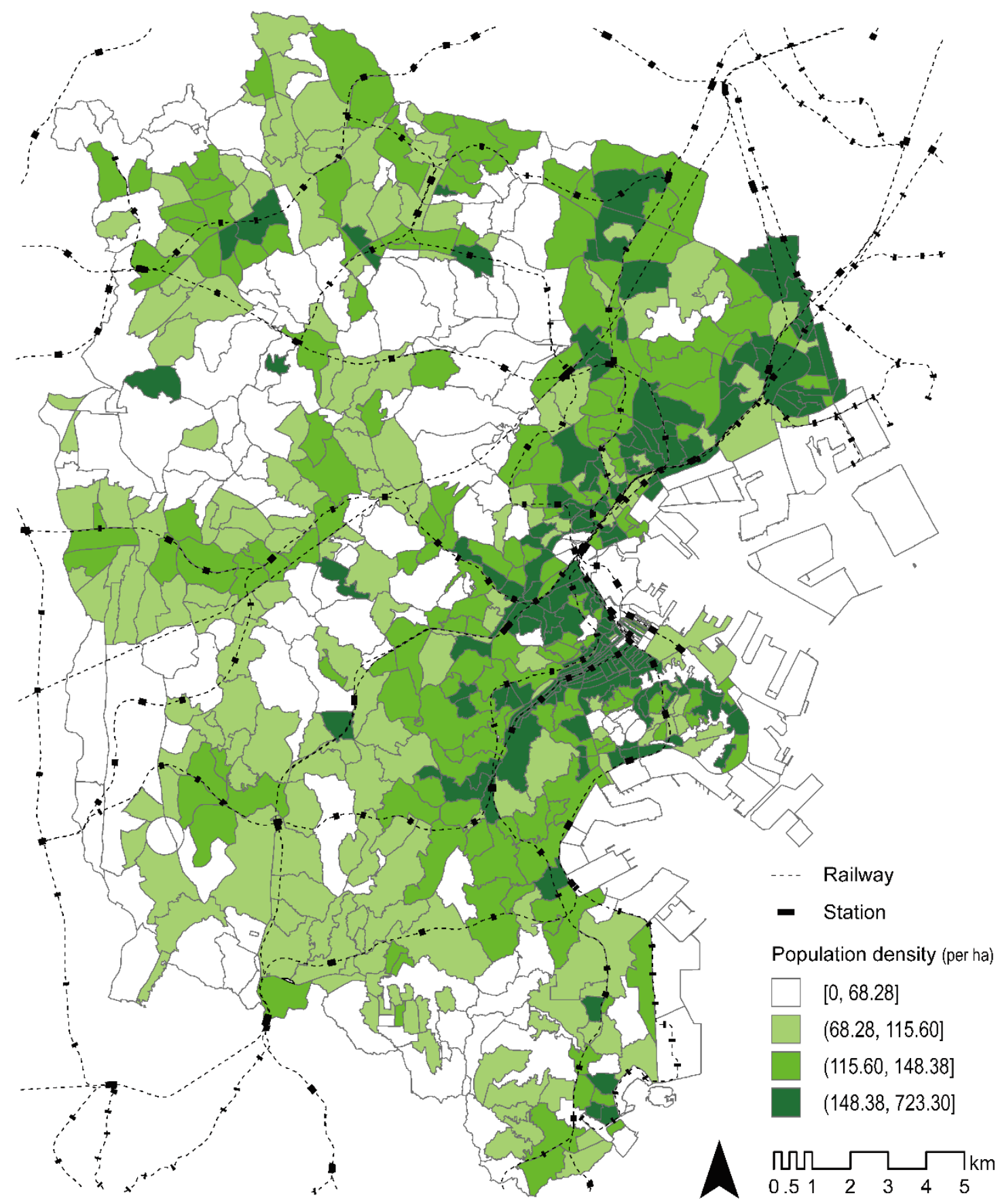

Figure 1. Target area (Yokohama City).

We selected the sample for the present study from among 303,629 YWPP participants (as of 31 March 2019). We excluded participants younger than 65 or older than $79(60.0 \%)$ as well as those with a recorded participation in March 2016 or March 2019 of less than 16 days (74.8\% and 75.0\%, respectively). Furthermore, we excluded participants with residential addresses outside Yokohama City (4.2\%), which reduced the sample to 22,357 participants. Finally, 101 participants whose postal codes had changed during the three-year period and 699 participants whose step count in March 2016 and/or March 2019 was in either the upper or lower 1\% of the remaining participants were excluded as outliers. The final analysis dataset of this study included data from 21,557 participants (Figure 2). 


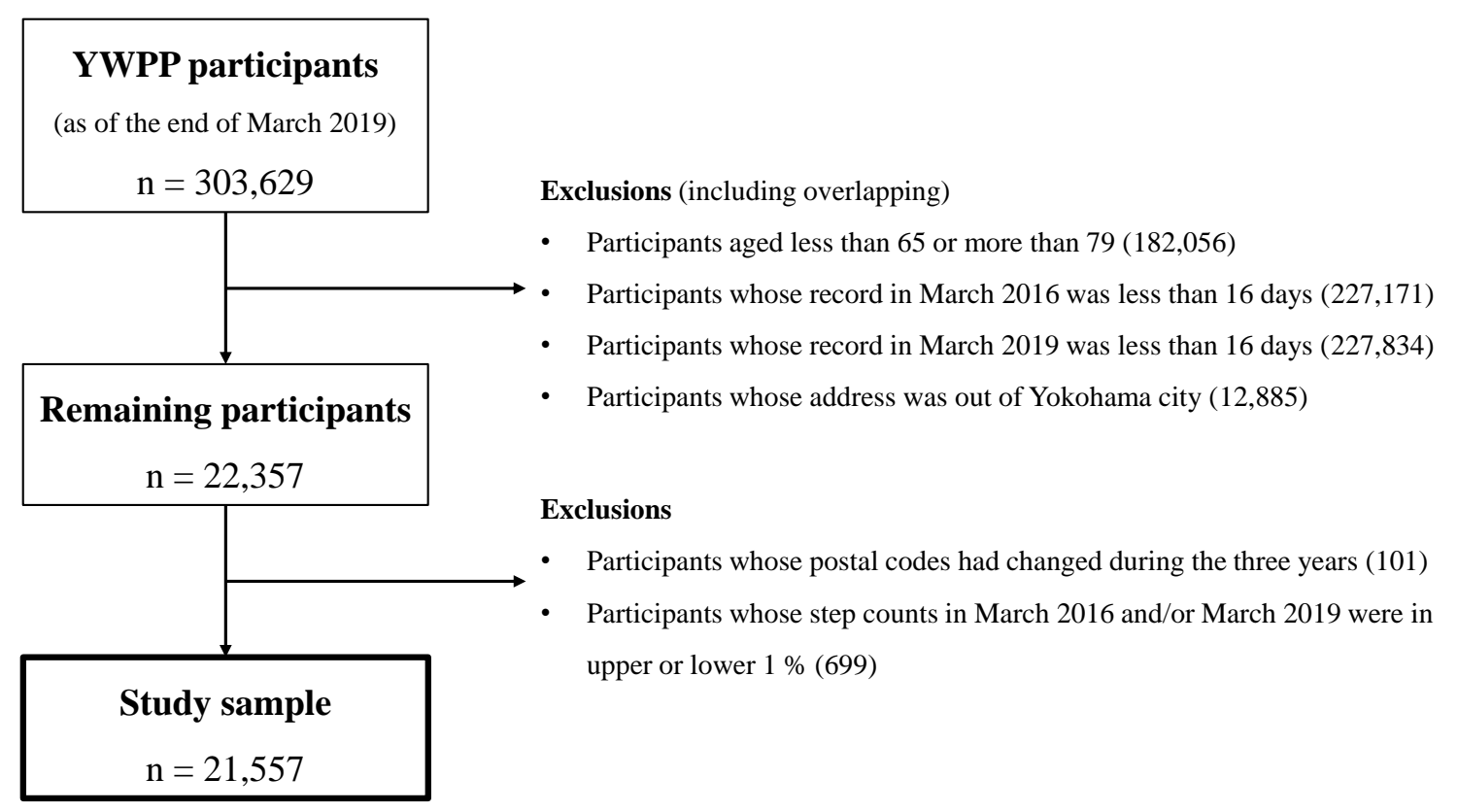

Figure 2. Sample selection flow diagram.

\subsection{Quantification of Built Environment and Control Variables}

We selected six BE variables on the basis of the 5Ds that were computed using ArcMap 10.6 (Esri, Redlands, CA) and used in the subsequent analyses. Neighborhoods were classified into quartiles for each $\mathrm{BE}$ variable.

First, we used the population density (per ha) as an index of density (Figure 1), which we calculated from the population census conducted in 2015. Second, we used the intersection density (per ha) as an index of design, as previously reported $[6,10,11]$. The Advanced Digital Road Map Database 2013 (Sumitomo Electric Industries, Ltd., Osaka, Japan) was the source of information. Third, we used the proportion of commercial land use (\%) as an index of diversity and destination that was calculated from the result of the Basic Surveys Concerning City Planning in 2013 conducted by Yokohama City. Fourth, we employed the normalized difference vegetation index (NDVI), from 2016, as another index of diversity and destination. The NDVI quantifies vegetation by measuring the difference between near-infrared light (which vegetation strongly reflects) and red light (which vegetation absorbs) and ranges from -1 to +1 . A positive NDVI indicates that the land cover is likely to be green vegetation, including parks and promenades, which can be potential recreational destinations for residents. However, a negative NDVI indicates that the land cover is likely to be street surfaces and buildings. The NDVI was selected as a BE variable because green land use was associated with the PA of older adults in both cross-sectional [31] and longitudinal studies [23]. Fifth, the average distance to the nearest railway station $(\mathrm{km})$ was used as an index of the distance to transit and destination, and was calculated from the data of the National Land Numerical Information download service obtained in 2018 [32]. Last, the average distance to the nearest bus stop $(\mathrm{km})$ was used as an index of the distance to transit, which was calculated from the data of the same service obtained in 2010. Given the shared role between railways and buses in Yokohama, as mentioned earlier, the average distance to the nearest railway station and bus stop should be separate variables; however, most previous studies did not separate the two [14,33]. As the precise address of each participant was unknown, the distance to the nearest railway station and bus stop from each participant's address was computed by measuring the distance from the 50 -m grid points within each neighborhood to calculate the average for each neighborhood.

Many studies have used a composite measure of walkability [16,24,34-37]. However, in this study, we used BE variables without compounding them, because composite measures have less utility for 
urban planners and designers as they cannot ascertain the effect of each BE variable. The control variables in both of the analyses included the sex and age group $(65-69,70-74$, and 75-79 years, as of March 2016) of the participants.

\subsection{Statistical Analysis}

As our data had a multilevel structure with individuals (Level One) nested within 758 neighborhoods (Level Two), we conducted multilevel regression analyses with random intercepts. The baseline step count and the change in step count during the three-year period were the outcome variables for the first and second analyses, respectively. The descriptive variables comprised the six BE variables and control variables of sex and age groups in the first analysis, and the baseline step count was included in the second analysis. The fourth quartile of six BE variables, female sex, and age of 75-79 years were set as the reference category. The significance level was set at $p<0.05$. All statistical analyses were conducted in IBM SPSS Statistics 26 (IBM Corp., Armonk, NY, USA).

\section{Results}

\subsection{Descriptive Statistics}

Table 1 presents the descriptive statistics of the study sample. Males constituted $48 \%$ of the sample. The age groups $65-69,70-74$, and $75-79$ constituted $43 \%, 35 \%$, and $22 \%$ of the sample, respectively. The average step count at the baseline was $7699.0 \pm 3252.1$, and the count at the endpoint was $6845.3 \pm 3252.1$, which indicated that the step count of the sample decreased by 850 steps, on average, during the three-year study period.

Table 1. Descriptive statistics of the sample $(N=21,557)$.

\begin{tabular}{|c|c|c|c|}
\hline \multicolumn{2}{|c|}{ Category } & $N$ & $\%$ \\
\hline \multirow{2}{*}{ Sex } & Male & 10,303 & 47.8 \\
\hline & Female & 11,254 & 52.2 \\
\hline \multirow{3}{*}{ Age (in years) } & $65-69$ & 9359 & 43.4 \\
\hline & $70-74$ & 7507 & 34.8 \\
\hline & $79-79$ & 4691 & 21.8 \\
\hline
\end{tabular}

Descriptive statistics of the BE variables of 758 neighborhoods are presented in Table 2. The median values of population density and intersection density per ha were 115.60 and 2.03, respectively. The proportion of commercial land use was generally low, with a median proportion of $3.3 \%$. The NDVI was positive in all neighborhoods. The median of the average distance to the nearest railway station and the nearest bus stop was 647 and $175 \mathrm{~m}$, respectively, which represents the convenience of public transportation in Yokohama.

Table 2. Descriptive statistics of built environment (BE) variables of 758 neighborhoods.

\begin{tabular}{cccccccc}
\hline Category & Min & Max & Mean & SD & 1st Quartile & Median & 3rd Quartile \\
\hline Population density (per ha) & 0 & 723.30 & 116.66 & 79.11 & 68.28 & 115.60 & 148.38 \\
Intersection density (per ha) & 0 & 7.72 & 2.09 & 1.18 & 1.33 & 2.03 & 2.76 \\
Proportion of commercial land use (\%) & 0 & 51.18 & 5.99 & 7.56 & 1.54 & 3.30 & 6.76 \\
NDVI & 0.01 & 0.34 & 0.08 & 0.05 & 0.05 & 0.08 & 0.10 \\
Average distance to the nearest & 0.07 & 3.99 & 0.82 & 0.62 & 0.36 & 0.65 & 1.06 \\
railway station $(\mathrm{km})$ & 0.06 & 1.72 & 0.20 & 0.10 & 0.14 & 0.18 & 0.23 \\
Bus stop $(\mathrm{km})$ &
\end{tabular}

SD, Standard Deviation; NDVI, Normalized Difference Vegetation Index.

\subsection{Multilevel Regression Analyses}

The results of the multilevel regression analyses are presented in Table 3. In the first analysis, with the outcome variable of the baseline step count, a higher population density and lower intersection 
density were associated with a higher baseline step count. The association between the average distance to the nearest railway station and baseline step count was nonlinear; however, the second shortest quartile $(\mathrm{Q} 2)$ was associated with a significantly higher baseline step count. Other BE variables, such as the proportion of commercial land use, the NDVI, and the average distance to the nearest bus stop, did not show significant associations.

Table 3. Associations between BE variables and step count (baseline and change) using multilevel regression $(N=21,557)$.

\begin{tabular}{|c|c|c|c|c|c|c|}
\hline \multirow[b]{2}{*}{ Category } & \multicolumn{3}{|c|}{ Baseline Step Count } & \multicolumn{3}{|c|}{ Change in Step Count } \\
\hline & $B$ & $95 \%$ CI & $p$ & $B$ & $95 \%$ CI & $p$ \\
\hline \multicolumn{7}{|l|}{$\mathrm{BE}$ variables } \\
\hline \multicolumn{7}{|c|}{ Population density (ref: Q4) } \\
\hline Q1 (Lowest) & -213.7 & $(-396,-31.3)$ & $0.022 *$ & -115.9 & $(-225.9,-5.9)$ & $0.039 *$ \\
\hline Q2 & -118.9 & $(-262.1,24.4)$ & 0.104 & -10.8 & $(-97.6,76)$ & 0.807 \\
\hline Q3 & -113.3 & $(-250.4,23.7)$ & 0.105 & -4.3 & $(-87.4,78.8)$ & 0.919 \\
\hline \multicolumn{7}{|c|}{ Intersection density (ref: Q4) } \\
\hline Q1 (Lowest) & 208.0 & $(52.5,363.4)$ & $0.009^{* *}$ & 87.9 & $(-5.4,181.3)$ & 0.065 \\
\hline Q2 & 50.7 & $(-75.6,177)$ & 0.430 & 129.7 & $(53.3,206.2)$ & $0.001^{* * *}$ \\
\hline$\hat{\mathrm{Q} 3}$ & -37.0 & $(-157.4,83.4)$ & 0.545 & 31.9 & $(-41,104.8)$ & 0.391 \\
\hline \multicolumn{7}{|c|}{ Average distance to the nearest railway station (ref: Q4) } \\
\hline Q1 (Shortest) & 120.5 & $(-49.2,290.2)$ & 0.163 & 130.7 & $(27.9,233.5)$ & $0.013 *$ \\
\hline Q2 & 200.0 & $(73.1,326.9)$ & $0.002 * *$ & 117.5 & $(40.7,194.3)$ & $0.003 * *$ \\
\hline Q3 & 110.0 & $(-3.8,223.8)$ & 0.058 & 117.1 & $(48.6,185.6)$ & $0.001^{* * *}$ \\
\hline \multicolumn{7}{|l|}{ Control variables } \\
\hline \multicolumn{7}{|l|}{ Sex (ref: Female) } \\
\hline Male & 1821.7 & $\begin{array}{c}\text { (1738.4, } \\
1905)\end{array}$ & $0.000^{* * *}$ & 358.6 & $(304.3,412.8)$ & $0.000^{* * *}$ \\
\hline \multicolumn{7}{|l|}{ Age (ref: 75-79) } \\
\hline $65-69$ & 815.4 & $(705.8,925)$ & $0.000 * * *$ & 314.9 & $(246.1,383.8)$ & $0.000 * * *$ \\
\hline $70-74$ & 460.7 & $(347,574.4)$ & $0.000^{* * *}$ & 154.0 & $(82.7,225.2)$ & $0.000^{* * *}$ \\
\hline Baseline step counts & - & - & - & -0.3 & $(-0.3,-0.3)$ & $0.000^{* * *}$ \\
\hline
\end{tabular}

$\mathrm{BE}$, built environment; $B$ : regression coefficient; $\mathrm{CI}$, confidence intervals; $p$ : statistical significance of coefficient $\left({ }^{*}<0.05,{ }^{* *}<0.01, * * *<0.001\right)$.

In the second analysis with the outcome variable of change in step count during the three years, the lowest quartile $(\mathrm{Q} 1)$ of population density was associated with a larger decline in the step count. In addition, a lower intersection density and shorter average distance to the nearest railway station were associated with a smaller decline in step count. However, the other three BE variables did not have significant associations.

With regard to control variables over the course of the study, female sex and older age were associated with a lower baseline step count and larger decline in the step count. Moreover, a higher baseline step count was associated with a larger decline.

\section{Discussion}

This study examined the association between the change in the step count of older adults and the neighborhood BE in Yokohama, Japan, over a three-year period. The main finding was that four of the 5Ds (Density, Design, Destination Accessibility, and Distance to Transit) were associated with a decline in older adults' step count. In addition, the association of the BE with baseline step count was examined. Comparisons of the results of the two models showed that the significant variables selected were mostly the same, and the direction of the coefficients was consistent in both models. Thus, the BEs of older adults were not only associated with their step count at a certain timepoint, but also widened the disparity of their step count over the three years. 
With regard to each variable, a lower population density was associated with a lower baseline step count, and older adults living in the lowest quartile neighborhoods of population density had a significant decrease in the step count during the three years. Population density ensures public transport and local shops and services are more viable [38] and serves as a proxy variable showing the convenience of walking for local residents. Accordingly, our result agrees with that of a three-year study in Québec, Canada, that proximity to local shops and services was associated with greater likelihood of frequent walking [22]. Cross-sectional studies on older Japanese adults that found an association between population density and their body mass index [39] and physical function [40] underpin our result. On the other hand, older adults in sparsely-populated and inconvenient areas might decrease their trip frequency or change their transportation mode from walking. It was estimated that the population of Yokohama reached its peak in 2019 and would begin declining as with other cities in Japan [41]. On a microscale level, areas that are inconvenient to reach in the city would experience a greater decrease in population, resulting in the withdrawal of facilities and even greater inconvenience to residents. Considering low residential mobility in Japan, especially that of older adults [42], health promotion interventions for PA would be necessary for such areas. Deployment planning of facilities that serve as third places to which older adults routinely walk and where they can socialize with others, would be important $[43,44]$.

Inversely, lower intersection density was associated with higher baseline step count and a smaller decline in step count over the course of the study. High intersection density indicates that there are many route opportunities for traversing a road network and is thought to promote walking [6], and previous cross-sectional studies have shown that there is a positive association between older adults' self-reported walking and intersection density $[10,11]$. In previous longitudinal studies, not limited to older adults, higher street connectivity proved to be associated with a greater increase in walking for transportation [45]. Although our results contradicted these studies, another study conducted in Japan stated that the number of intersections was negatively associated with walking time [46]. It may be that intersection density cannot be an index of walkability in a city with high intersection density, such as Yokohama. The intersection density in Yokohama is approximately twice this figure compared to 100 cities all over the world, excluding Japanese cities, and as high as the highest city (Lisbon, Portugal) in developed countries [47]. Considering a previous study that showed that the number of street intersections contributed to walking activity only when residents perceived that the traffic conditions were safe [11], older adults in neighborhoods with a high intersection density in this study might feel unsafe, as the intersection density acted as an index of traffic accident risk. The installation of more traffic light buttons for people who walk slowly, especially older pedestrians, should be considered for their safety.

With regard to the average distance to the nearest railway station, older adults living in the second closest quartile neighborhood recorded a significantly higher baseline step count, which suggests that they could not walk much when living too close to stations. A walkable design where older adults feel safe and are more willing to walk around is desirable around railway stations. More importantly, it was found that older adults living closer to railway stations experienced a smaller decline in step count. Taking this into consideration with a previous study of older Japanese that showed a lower risk of functional limitations among those using public transport after driving cessation [48], closeness to railway stations would enable older adults to maintain their active living, their step count, and their health even after they give up driving. Yokohama City aims to accumulate residential functions around railway stations, even in suburban areas, as well as commercial and business functions [49]. Such a compact city policy, which is thought to positively influence the overall health of city populations [50], would be more beneficial in an aging society such as Yokohama City, provided that consideration is given to outskirt areas, as noted earlier.

The other BE variables, including the proportion of commercial land use, the NDVI, and the average distance to the nearest bus stop, were not significantly associated with step counts in either regression analyses. This inconsistency with a previous study in Norfolk, United Kingdom, which 
reported that neighborhood greenspace may be protective against a decline in older people's PA [23], seemed to be due to the difference of the degree of urbanization. With regard to personal attributes, females and participants in the older group recorded a lower baseline step count and a larger decline over the course of the study. Furthermore, a higher baseline step count was associated with a larger decline, which was consistent with the results from a previous study [19]. Similar results are expected in other Japanese megacities with high population density and developed railway network (e.g., Tokyo, Osaka, and Nagoya); however, it should be reexamined when pedometer data from as large a sample as this study are obtained in other cities.

This study makes an important contribution to existing research on BE factors that mitigate the decline in the step count of older adults, although it has some limitations. For instance, previous studies showed social environmental factors, such as neighborhood cohesion [51], income deprivation [52], participation with friends [53], social support [35], and neighbor relationships [54], were associated with walking behaviors and/or PA. Unfortunately, this study was not able to assess the impact of social environments of older adults as it is difficult to collect data on social environmental factors from a large sample. Therefore, future studies should consider them when examining the longitudinal association between changes in the PA of older adults. In addition, study participants may not be representative of the general population of Yokohama City in that they were motivated to have pedometers, suggesting a greater intention to walk than others, although approximately $20 \%$ of citizens in the age group of 65-79 participated in the program. We thought that study participants would be less affected by the BE because of their higher motivation and that the effect of the BE would be underestimated in this study.

\section{Conclusions}

This three-year study examined the longitudinal association between the change in step count of 21,557 older adults and the neighborhood BEs in Yokohama, Japan, using multilevel regression analysis. The main finding of this study was that the neighborhood BEs of older adults were not only associated with their step count at a certain time but also widened the disparity in the step count over the three years, which had not been examined in previous cross-sectional studies or those using self-reported data on PA. It is essential that urban planners and designers create compact cities located around railway stations that are protected from traffic to ensure the safety of older adults. Our findings, providing insights into the relationship between neighborhood BEs and health behavior of older adults, could contribute to creating such age-friendly cities where older adults can maintain and promote their health.

Author Contributions: Conceptualization, K.H.; Formal analysis, K.H.; Funding acquisition, K.H.; Writing—original draft, K.H.; Writing—review and editing, H.U. and M.H. All authors have read and agreed to the published version of the manuscript.

Funding: This research was supported by JSPS KAKENHI, grant number 18H01602.

Acknowledgments: The authors thank the staff of Yokohama City for their generous support of this research and T. Miyagawa for helping us with data collection. Due to a confidentiality agreement with survey respondents, raw data of the questionnaire cannot be shared.

Conflicts of Interest: The authors declare no conflict of interest.

Data Availability Statement: The data that support the findings of this study are able to be obtained from Yokohama City, but restrictions apply to the availability of these data. They were used under an agreement for the current study, and so are not publicly available.

\section{References}

1. Lee, I.-M.; Shiroma, E.J.; Lobelo, F.; Puska, P.; Blair, S.N.; Katzmarzyk, P.T. Effect of physical inactivity on major non-communicable diseases worldwide: An analysis of burden of disease and life expectancy. Lancet 2012, 380, 219-229. [CrossRef]

2. World Health Organization. Global Action Plan on Physical Activity 2018-2030: More Active People for a Healthier World; World Health Organization: Geneva, Switzerland, 2018. 
3. Sallis, J.F.; Bull, F.; Guthold, R.; Heath, G.W.; Inoue, S.; Kelly, P.; Oyeyemi, A.L.; Perez, L.G.; Richards, J.; Hallal, P.C. Progress in physical activity over the Olympic quadrennium. Lancet 2016, 388, 1325-1336. [CrossRef]

4. Sallis, J.F.; Bull, F.; Burdett, R.; Frank, L.D.; Griffiths, P.; Giles-Corti, B.; Stevenson, M. Use of science to guide city planning policy and practice: How to achieve healthy and sustainable future cities. Lancet 2016, 388, 2936-2947. [CrossRef]

5. Giles-Corti, B.; Vernez-Moudon, A.; Reis, R.; Turrell, G.; Dannenberg, A.L.; Badland, H.; Foster, S.; Lowe, M.; Sallis, J.F.; Stevenson, M.; et al. City planning and population health: A global challenge. Lancet 2016, 388, 2912-2924. [CrossRef]

6. Cervero, R.; Sarmiento, O.L.; Jacoby, E.; Gomez, L.F.; Neiman, A. Influences of built environments on walking and cycling: Lessons from Bogotá. Int. J. Sustain. Transp. 2009, 3, 203-226. [CrossRef]

7. Bloomberg, M.R. Active Design Guidelines, Promoting Physical Activity and Health in Design; Wiley: New York, NY, USA, 2010.

8. Kim, S.; Ulfarsson, G.F. Activity Space of Older and Working-Age Adults in the Puget Sound Region, Washington. Transp. Res. Rec. J. Transp. Res. Board 2015, 2494, 37-44. [CrossRef]

9. Kerr, J.; Rosenberg, D.; Frank, L. The Role of the Built Environment in Healthy Aging: Community Design, Physical Activity, and Health among Older Adults. J. Plan. Lit. 2012, 27, 43-60. [CrossRef]

10. Troped, P.J.; Tamura, K.; McDonough, M.H.; Starnes, H.A.; James, P.; Ben-Joseph, E.; Cromley, E.; Puett, R.; Melly, S.J.; Laden, F. Direct and Indirect Associations Between the Built Environment and Leisure and Utilitarian Walking in Older Women. Ann. Behav. Med. 2017, 51, 282-291. [CrossRef]

11. Li, F.; Fisher, K.J.; Brownson, R.C.; Bosworth, M. Multilevel modelling of built environment characteristics related to neighbourhood walking activity in older adults. J. Epidemiol. Community Health 2005, 59, 558-564. [CrossRef]

12. Kolbe-Alexander, T.L.; Pacheco, K.; Tomaz, S.A.; Karpul, D.; Lambert, E.V. The relationship between the built environment and habitual levels of physical activity in South African older adults: A pilot study Health behavior, health promotion and society. BMC Public Health 2015, 15, 518. [CrossRef]

13. Van Holle, V.; Van Cauwenberg, J.; Gheysen, F.; Van Dyck, D.; Deforche, B.; Van De Weghe, N.; De Bourdeaudhuij, I. The association between Belgian older adults' physical functioning and physical activity: What is the moderating role of the physical environment? PLoS ONE 2016, 11, e0148398. [CrossRef] [PubMed]

14. Nyunt, M.S.Z.; Shuvo, F.K.; Eng, J.Y.; Yap, K.B.; Scherer, S.; Hee, L.M.; Chan, S.P.; Ng, T.P. Objective and subjective measures of neighborhood environment (NE): Relationships with transportation physical activity among older persons. Int. J. Behav. Nutr. Phys. Act. 2015, 12, 108. [CrossRef] [PubMed]

15. Etman, A.; Kamphuis, C.B.M.; Prins, R.G.; Burdorf, A.; Pierik, F.H.; van Lenthe, F.J. Characteristics of residential areas and transportational walking among frail and non-frail Dutch elderly: Does the size of the area matter? Int. J. Health Geogr. 2014, 13, 7. [CrossRef] [PubMed]

16. Clarke, P.; Gallagher, N.A. Optimizing mobility in later life: The role of the urban built environment for older adults aging in place. J. Urban Health 2013, 90, 997-1009. [CrossRef]

17. Cerin, E.; Nathan, A.; van Cauwenberg, J.; Barnett, D.W.; Barnett, A. The neighbourhood physical environment and active travel in older adults: A systematic review and meta-analysis. Int. J. Behav. Nutr. Phys. Act. 2017, 14, 15. [CrossRef]

18. Barnett, D.W.; Barnett, A.; Nathan, A.; Van Cauwenberg, J.; Cerin, E. Built environmental correlates of older adults' total physical activity and walking: A systematic review and meta-analysis. Int. J. Behav. Nutr. Phys. Act. 2017, 14, 103. [CrossRef]

19. Li, F.; Fisher, K.J.; Brownson, R.C. A multilevel analysis of change in neighborhood walking activity in older adults. J. Aging Phys. Act. 2005, 13, 145-159. [CrossRef]

20. Michael, Y.L.; Perdue, L.A.; Orwoll, E.S.; Stefanick, M.L.; Marshall, L.M. Physical activity resources and changes in walking in a cohort of older men. Am. J. Public Health 2010, 100, 654-660. [CrossRef]

21. Zhou, P.; Grady, S.C.; Chen, G. How the built environment affects change in older people's physical activity: A mixed-methods approach using longitudinal health survey data in urban China. Soc. Sci. Med. 2017, 192, 74-84. [CrossRef] 
22. Gauvin, L.; Richard, L.; Kestens, Y.; Shatenstein, B.; Daniel, M.; Moore, S.D.; Mercille, G.; Payette, H. Living in a well-serviced urban area is associated with maintenance of frequent walking among seniors in the VoisiNuAge study. J. Gerontol. Ser. B Psychol. Sci. Soc. Sci. 2012, 67, 76-88. [CrossRef]

23. Dalton, A.M.; Wareham, N.; Griffin, S.; Jones, A.P. Neighbourhood greenspace is associated with a slower decline in physical activity in older adults: A prospective cohort study. SSM Popul. Health 2016, 2, 683-691. [CrossRef] [PubMed]

24. Kikuchi, H.; Nakaya, T.; Hanibuchi, T.; Fukushima, N.; Amagasa, S.; Oka, K.; Sallis, J.F.; Inoue, S. Objectively measured neighborhood walkability and change in physical activity in older Japanese adults: A five-year cohort study. Int. J. Environ. Res. Public Health 2018, 15, 1814. [CrossRef] [PubMed]

25. Kärmeniemi, M.; Lankila, T.; Ikäheimo, T.; Koivumaa-Honkanen, H.; Korpelainen, R. The Built Environment as a Determinant of Physical Activity: A Systematic Review of Longitudinal Studies and Natural Experiments. Ann. Behav. Med. 2018, 52, 239-251. [CrossRef] [PubMed]

26. Senso, M.M.; Anderson, C.P.; Crain, A.L.; Sherwood, N.E.; Martinson, B.C. Self-reported Activity and Accelerometry in 2 Behavior-maintenance Trials. Am. J. Health Behav. 2014, 38, 254-264. [CrossRef]

27. Zacharias, J.; Zhang, T.; Nakajima, N. Tokyo Station City: The railway station as urban place. Urban Des. Int. 2011, 16, 242-251. [CrossRef]

28. Hino, K.; Taniguchi, A.; Hanazato, M.; Takagi, D. Modal shift from cars and promotion of walking by providing pedometers in Yokohama city, Japan. Int. J. Environ. Res. Public Health 2019, 16, 2144. [CrossRef]

29. Japan Meteorological Agency Meteorological Data Search Service. Available online: http://www.jma.go.jp/ jma/ (accessed on 8 March 2020).

30. Hino, K.; Lee, J.S.; Asami, Y. Associations between seasonal meteorological conditions and the daily step count of adults in Yokohama, Japan: Results of year-round pedometer measurements in a large population. Prev. Med. Rep. 2017, 8, 15-17. [CrossRef]

31. Gong, Y.; Gallacher, J.; Palmer, S.; Fone, D. Neighbourhood green space, physical function and participation in physical activities among elderly men: The Caerphilly Prospective study. Int. J. Behav. Nutr. Phys. Act. 2014, 11, 40. [CrossRef]

32. Ministry of Land Infrastructure Transport and Tourism National Land Numerical Information Download Service. Available online: http://nlftp.mlit.go.jp/ksj/index.html (accessed on 16 March 2019).

33. Todd, M.; Adams, M.A.; Kurka, J.; Conway, T.L.; Cain, K.L.; Buman, M.P.; Frank, L.D.; Sallis, J.F.; King, A.C. GIS-measured walkability, transit, and recreation environments in relation to older Adults' physical activity: A latent profile analysis. Prev. Med. Baltim. 2016, 93, 57-63. [CrossRef]

34. Gao, J.; Fu, H.; Li, J.; Jia, Y. Association between social and built environments and leisure-time physical activity among Chinese older adults-A multilevel analysis Energy balance-related behaviours. BMC Public Health 2015, 15, 1317. [CrossRef]

35. Carlson, J.A.; Sallis, J.F.; Conway, T.L.; Saelens, B.E.; Frank, L.D.; Kerr, J.; Cain, K.L.; King, A.C. Interactions between psychosocial and built environment factors in explaining older adults' physical activity. Prev. Med. Baltim. 2012, 54, 68-73. [CrossRef] [PubMed]

36. Chudyk, A.M.; McKay, H.A.; Winters, M.; Sims-Gould, J.; Ashe, M.C. Neighborhood walkability, physical activity, and walking for transportation: A cross-sectional study of older adults living on low income. BMC Geriatr. 2017, 17, 82. [CrossRef] [PubMed]

37. Hanibuchi, T.; Nakaya, T.; Yonejima, M.; Honjo, K. Perceived and objective measures of neighborhood walkability and physical activity among adults in Japan: A multilevel analysis of a nationally representative sample. Int. J. Environ. Res. Public Health 2015, 12, 13350-13364. [CrossRef] [PubMed]

38. Udell, T.; Daley, M.; Johnson, B.; Tolley, D.R. Does Density Matter? The Role of Density in Creating Walkable Neighbourhoods; National Heart Foundation of Australia: Melbourne, Australia, 2014.

39. Koohsari, M.J.; McCormack, G.R.; Nakaya, T.; Shibata, A.; Ishii, K.; Yasunaga, A.; Liao, Y.; Oka, K. Walking-friendly built environments and objectively measured physical function in older adults. J. Sport Health Sci. 2020. [CrossRef]

40. Koohsari, M.J.; Kaczynski, A.T.; Nakaya, T.; Shibata, A.; Ishii, K.; Yasunaga, A.; Stowe, E.W.; Hanibuchi, T.; Oka, K. Walkable Urban Design Attributes and Japanese Older Adults' Body Mass Index: Mediation Effects of Physical Activity and Sedentary Behavior. Am. J. Health Promot. 2019, 33, 764-767. [CrossRef]

41. Yokohama City. Population Estimation in Yokohama. Available online: https:/www.city.yokohama.lg.jp/ city-info/seisaku/torikumi/shien/jinkosuikei.html (accessed on 22 March 2020). 
42. Chiuri, M.C.; Jappelli, T. Do the elderly reduce housing equity? An international comparison. J. Popul. Econ. 2010, 23, 643-663. [CrossRef]

43. Sakamoto, S.; Ando, S.; Hino, K. Relationship between third places and needing long-term care of the late elderly in the suburb. J. Environ. Eng. Trans. AIJ 2019, 84, 577-586. [CrossRef]

44. Lee, J.H.; Tan, T.H. Neighborhood walkability or third places? Determinants of social support and loneliness among older adults. J. Plan. Educ. Res. 2019. [CrossRef]

45. Knuiman, M.W.; Divitini, M.L.; Foster, S.A.; Christian, H.E.; Giles-Corti, B.; Bull, F.C.; Badland, H.M.; Divitini, M.L.; Foster, S.A.; Bull, F.C.; et al. A Longitudinal Analysis of the Influence of the Neighborhood Built Environment on Walking for Transportation: The RESIDE Study. Am. J. Epidemiol. 2014, 180, 453-461. [CrossRef]

46. Hanibuchi, T.; Kawachi, I.; Nakaya, T.; Hirai, H.; Kondo, K. Neighborhood built environment and physical activity of Japanese older adults: Results from the Aichi Gerontological Evaluation Study (AGES). BMC Public Health 2011, 11, 657. [CrossRef]

47. Rashid, M. The Geometry of Urban Layouts; Springer International Publishing: Cham, Switzerland, 2017; ISBN 978-3-319-30748-0.

48. Hirai, H.; Ichikawa, M.; Kondo, N.; Kondo, K. The Risk of Functional Limitations After Driving Cessation among Older Japanese Adults: The JAGES Cohort Study. J. Epidemiol. 2019. [CrossRef] [PubMed]

49. Yokohama City. Yokohama City Transportation Plan; Yokohama City: Yokohama, Japan, 2018.

50. Stevenson, M.; Thompson, J.; de Sá, T.H.; Ewing, R.; Mohan, D.; McClure, R.; Roberts, I.; Tiwari, G.; Giles-Corti, B.; Sun, X.; et al. Land use, transport, and population health: Estimating the health benefits of compact cities. Lancet 2016, 388, 2925-2935. [CrossRef]

51. Li, Y.; Kao, D.; Dinh, T.Q. Correlates of neighborhood environment with walking among older Asian Americans. J. Aging Health 2015, 27, 17-34. [CrossRef] [PubMed]

52. Hawkesworth, S.; Silverwood, R.J.; Armstrong, B.; Pliakas, T.; Nanchalal, K.; Jefferis, B.J.; Sartini, C.; Amuzu, A.A.; Wannamethee, S.G.; Ramsay, S.E.; et al. Investigating associations between the built environment and physical activity among older people in 20 UK towns. J. Epidemiol. Community Health 2018, 72, 121-131. [CrossRef] [PubMed]

53. Chaudhury, H.; Campo, M.; Michael, Y.; Mahmood, A. Neighbourhood environment and physical activity in older adults. Soc. Sci. Med. 2016, 149, 104-113. [CrossRef]

54. Seino, S.; Kitamura, A.; Nishi, M.; Tomine, Y.; Tanaka, I.; Taniguchi, Y.; Yokoyama, Y.; Amano, H.; Narita, M.; Ikeuchi, T.; et al. Individual- and community-level neighbor relationships and physical activity among older Japanese adults living in a metropolitan area: A cross-sectional multilevel analysis. Int. J. Behav. Nutr. Phys. Act. 2018, 15, 46. [CrossRef] [PubMed]

(C) 2020 by the authors. Licensee MDPI, Basel, Switzerland. This article is an open access article distributed under the terms and conditions of the Creative Commons Attribution (CC BY) license (http://creativecommons.org/licenses/by/4.0/). 